\title{
Managerial and program inefficiency for European meat manufacturing firms: A dynamic multidirectional inefficiency analysis approach
}

\author{
Magdalena Kapelko ${ }^{1}{ }^{1}$ - Alfons Oude Lansink ${ }^{2}$
}

Published online: 17 October 2017

(C) The Author(s) 2017. This article is an open access publication

\begin{abstract}
This paper proposes a dynamic multidirectional inefficiency analysis approach within the context of Data Envelopment Analysis to measuring input- and investmentspecific managerial and program inefficiency for groups of firms characterized by different technologies. Dynamic managerial inefficiency refers to the distance to the firms' group-specific dynamic frontier of best practices, and dynamic program inefficiency measures the difference between the group-specific dynamic frontier and the pooled dynamic frontier. The empirical application focuses on panel data of large meat processing firms in Eastern, Western and Southern Europe over the period 2005-2012. The results show that Eastern European firms have the highest dynamic managerial inefficiency for all inputs, but have the smallest values for dynamic program inefficiency. Western European firms perform worst in terms of program inefficiency for all inputs, while Southern European firms are the best with regard to dynamic managerial inefficiency. The results also reveal that regardless the dynamic inefficiency dimension considered, investments is the most inefficient input, followed by labor, and materials.
\end{abstract}

Keywords Data Envelopment Analysis · Program inefficiency $\cdot$ Managerial inefficiency $\cdot$ Dynamic inefficiency $\cdot$ Multi-directional inefficiency $\cdot$ Meat processing industry

Magdalena Kapelko

magdalena.kapelko@ue.wroc.pl

1 Institute of Applied Mathematics, Department of Logistics, Wroclaw University of Economics, Wroclaw, Poland

2 Business Economics Group, Wageningen University, Wageningen, The Netherlands
JEL classification $\mathrm{C} 44 \cdot \mathrm{C} 61 \cdot \mathrm{D} 92 \cdot \mathrm{L} 66$

\section{Introduction}

Since the seminal work by Charnes et al. (1981), the measurement of efficiency for groups of firms that are characterized by different technologies received a considerable attention in the efficiency and productivity literature. Charnes et al. (1981) proposed an approach within the context of Data Envelopment Analysis (DEA), to distinguish between managerial and program efficiency. Managerial efficiency is assessed in relation to the firm's group-specific frontier, and program efficiency measures the difference between the group-specific frontier and the frontier composed of all observations. These ideas were renewed by Battese et al. (2004) in the context of stochastic frontier analysis by introducing the concept of a metafrontier that spans all observations and represents the potential technology available for all firms regardless the group they belong to. O'Donnell et al. (2008) applied the metafrontier framework with DEA method ${ }^{1}$. The empirical applications of program and managerial efficiency and metafrontier include the analysis of educational performance (Portela and Thanassoulis 2001; Mancebón et al. 2012), agriculture (BeltránEsteve and Reig-Martínez 2014; Asmild et al. 2016), ecological performance (Gómez-Limón et al. 2012; Yao et al. 2015; Zhang et al. 2015) or banks (Zhu et al. 2015).

\footnotetext{
${ }^{1}$ Battese et al. (2004) and O'Donnell et al. (2008) define also a group efficiency which general idea is equivalent to managerial efficiency in the sense of Charnes et al. (1981). Furthermore, the idea of technology gaps between particular technologies introduced by Battese et al. (2004) (labelled as the metatechnology ratio in O'Donnell et al. (2008)) is equivalent to the concept of program efficiency in Charnes et al. (1981).
} 
On the other hand, the measurement of dynamic efficiency is a recent theme in the Data Envelopment Analysis literature $^{2}$. The general idea behind this approach is to assume that firms' production decisions are linked over time. Dynamic efficiency models developed in the literature along two strands. One group of studies within this line develop dynamic network models which take the view of multistage production systems (for example, Färe and Grosskopf 1996; Chen 2009; Fukuyama and Weber 2015). In the other group of studies, the firms' production decisions are linked over time through adjustment costs associated with changes in quasi-fixed factors of production (Silva and Stefanou 2003, 2007; Kapelko et al. 2014; Silva et al. 2015) ${ }^{3}$.

Previous studies did not consider the dynamics of firms production decisions when developing models for measuring the efficiency of groups of firms functioning under heterogeneous technologies. To fill in this gap, this paper combines the concepts of managerial and program efficiency with dynamic efficiency measurement. Therefore, the main aim of the paper is to develop a dynamic production framework for making comparisons across groups of firms (program inefficiency) and within groups of firms (managerial inefficiency). The introduction of production dynamics in models of efficiency is based on Silva and Stefanou (2003, 2007) who estimate hyperbolic efficiency measures, and their further extensions to dynamic directional distance functions by Serra et al. (2011), Kapelko et al. (2014) and Silva et al. (2015). Furthermore, this paper builds on the study of Kapelko and Oude Lansink (2017), who developed a dynamic multidirectional inefficiency model (dynamic MEA), but did not distinguish program inefficiency from managerial inefficiency ${ }^{4}$. It also builds on the study of Asmild et al. (2016) that developed the measures of program and managerial efficiency, but in the context of static MEA. In addition, the developed method allows for the analysis of inefficiency with regard to specific inputs employed in the firms' production process as well as for investments undertaken by firms ${ }^{5}$.

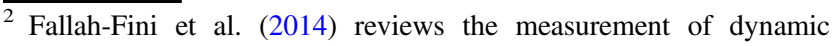
efficiency.

3 In addition, Nemoto and Goto $(1999,2003)$ propose dynamic DEA in which quasi-fixed inputs at the end of a time period are treated as if they were outputs in that period.

${ }^{4}$ Dynamic multidirectional inefficiency extends the MEA approach that was developed in the static context by Bogetoft and Hougaard (1999) and Asmild et al. (2003) and further developed by Bogetoft and Hougaard (2004), Asmild and Pastor (2010), Asmild et al. (2016) and Baležentis and De Witte (2015).

5 The literature on measuring input-specific efficiency also distinguishes studies that built on the Russell measure of efficiency (Färe and Lovell 1978) or directional slacks-based measure of efficiency (Fukuyama and Weber 2009; Färe and Grosskopf 2010). See, for example, the studies of Oude Lansink and Ondersteijn (2006) or Kapelko (2017a). The input-specific productivity growth measures are also derived, for example in the studies of Mahlberg and Sahoo (2011) or Kapelko et al. (2015).
}

The empirical application focuses on panel data from large firms in the meat processing industry in the European Union (EU) over the period 2005-2012 grouped into three regions: Eastern, Western and Southern EU firms. Meat processing in the EU is the largest sector within the food manufacturing industry in terms of turnover and the second largest after the manufacturing of bakery and farinaceous products in terms of value added and employment (Eurostat, 2015). It is a sector that is subject to EU regulations on environmental protection, animal welfare and food safety, as well as it is impacted by the changes in consumer preferences (Van Horne and Bondt 2013; European Commission 2011). Food safety regulation, mainly manifested through the General Food Law introduced in 2002, was enacted due to the occurrence of food crisis such as for example Bovine spongiform encephalopathy (BSE). At the same time, the trade in agricultural products is rapidly liberalizing, posing another challenge for this industry (European Commission 2011). Another important factor is financial crisis of the late 2008 that affected this industry mainly through the decrease in turnover of its constituting firms. EU meat manufacturing industry is rather heterogeneous across countries and regions, having different characteristics and modes of operating, for example, Eastern European meat manufacturing firms have a much lower market share and turnover compared to their Southern and Western counterparts. Furthermore, Southern European firms operate in supply chains that are more integrated than Eastern and Western European firms; also most consolidation and concentration is taking place among Western European firms (European Commission 2011; Wijnands 2007). Within this background, it is of interest to know whether the efficiency levels of inputs and investments were affected and whether meat processing firms from different regions in the EU were affected differently. In the context of increased regulation and increased production costs of meat manufacturing firms, it is also interesting to know the efficiency of particular inputs employed in the firms' production process. Finally, the differences in functioning of meat manufacturing industry in EU regions could be related to technical inefficiency, making this sector a proper case for the analysis of managerial and program inefficiency.

The rest of the paper proceeds as follows. Section "Methods" develops the method for computing dynamic multi-directional managerial and program inefficiency. Sections "Descriptions of the data" and "Results" describe the dataset and discuss the main findings, respectively. Section "Conclusions" presents the conclusions and discusses business and policy implications and future research lines. 


\section{Method}

\subsection{Computing pooled dynamic multi-directional inefficiency}

We begin by pooling all firms together regardless the group they belong to. That will allow computing pooled dynamic multi-directional inefficiency, that is inefficiency with regard to the dynamic frontier composed of all observations in the sample.

Let us assume a set of $j=1, \ldots, J$ firms using a vector of $N$ variable inputs $x=\left(x_{1}, \ldots, x_{N}\right)$, a vector of $F$ gross investments in quasi-fixed inputs $I=\left(I_{1}, \ldots, I_{F}\right)$, and a vector of $F$ quasi-fixed inputs $k=\left(k_{1}, \ldots, k_{F}\right)$ to produce a vector of $M$ outputs $y=\left(y_{1}, \ldots, y_{M}\right)$. The dynamic production technology transforms variable inputs and gross investments into outputs at a given level of quasi-fixed inputs and is defined as (see Kapelko et al. 2014; Silva et al. 2015):

$P=\{(x, I, y, k): x, I$ can produce $y$, given $k\}$

The dynamic production technology satisfies the properties that are summarized in Silva and Stefanou (2003).

An input-oriented dynamic MEA is based on two sequential steps. In the first step an ideal reference point with regard to investments and variable inputs $\left(x_{n}^{*}, I_{f}^{*}\right)$ for the $\mathrm{DMU}^{0}$ under analysis $\left(x_{n}^{0}, I_{f}^{0}, y_{m}^{0}\right)$ is determined using DEA by solving linear programmes for each variable input $n(=1, \ldots, N)$ :

$$
\begin{aligned}
& x_{n}^{*}=\min _{x_{n}, x^{i}} x_{n} \\
& \sum_{j=1}^{J} \lambda^{j} y_{m}^{j} \geq y_{m}^{0}, \quad \quad m=1, \ldots, M \\
& \sum_{j=1}^{J} \lambda^{j} x_{n}^{j} \leq x_{n} \\
& \sum_{j=1}^{J} \lambda^{j} x^{j}{ }_{-n} \leq x_{-n}^{0} \quad-n=1, \ldots, n-1, n+1, \ldots, N \\
& \sum_{j=1}^{J} \lambda^{j}\left(I_{f}^{j}-\delta k_{f}^{j}\right) \geq I_{f}^{0}-\delta k_{f}^{0} \quad f=1, \ldots, F \\
& \lambda^{j} \geq 0 \quad j=1, \ldots, J
\end{aligned}
$$

and for each investment $f(=1, \ldots, F)$ :

$$
\begin{aligned}
& I_{f}^{*}=\max _{I_{f}, \lambda^{i}} I_{f} \\
& \text { s.t. } \\
& \begin{array}{ll}
\sum_{j=1}^{J} \lambda^{j} y_{m}^{j} \geq y_{m}^{0}, & m=1, \ldots, M \\
\sum_{j=1}^{J} \lambda^{j} x_{n}^{j} \leq x_{n}^{0} & n=1, \ldots, N \\
\sum_{j=1}^{J} \lambda^{j}\left(I_{f}^{j}-\delta k_{f}^{j}\right) \geq I_{f}-\delta k_{f}^{0} & \\
\sum_{j=1}^{J} \lambda^{j}\left(I_{-f}^{j}-\delta k_{-f}^{j}\right) \geq I_{-f}^{0}-\delta k_{-f}^{0} & -f=1, \ldots, f-1, f+1, \ldots, F \\
\lambda^{j} \geq 0 & j=1, \ldots, J
\end{array}
\end{aligned}
$$

where $x_{-n}^{0}$ and $I_{-f}^{0}$ are vectors of all variable inputs except input $n$ and all investments except investment $f$, respectively, $\lambda^{j}$ are intensity weights, $\delta$ denotes firmspecific depreciation rates, $x_{n}^{*}$ and $I_{f}^{*}$ denote the optimal solutions of models (2) and (3), respectively, $x_{n}$ and $I_{f}$ denote the target values for the $n$th input reduction and the $f$ th investment expansion, respectively. The programs (2) and (3) assume a constant returns to scale (CRS) technology ${ }^{6}$.

In the second step, the following DEA model is solved:

$$
\begin{aligned}
& \beta^{*}=\max _{\beta, \lambda} \beta \\
& \text { s.t. } \\
& \begin{array}{ll}
\sum_{j=1}^{J} \lambda^{j} y_{m}^{j} \geq y_{m}^{0}, & m=1, \ldots, M \\
\sum_{j=1}^{J} \lambda^{j} x_{n}^{j} \leq x_{n}^{0}-\beta\left(x_{n}^{0}-x_{n}^{*}\right) & n=1, \ldots, N \\
\sum_{j=1}^{J} \lambda^{j}\left(I_{f}^{j}-\delta k_{f}^{j}\right) \geq I_{f}^{0}-\delta k_{f}^{0}+\beta\left(I_{f}^{*}-I_{f}^{0}\right) & f=1, \ldots, F \\
\lambda^{j} \geq 0 & j=1, \ldots, J
\end{array}
\end{aligned}
$$

where $\beta$ indicates the proportion by which variable inputs can be contracted and investments can be expanded relative to the ideal point, that is technical inefficiency of $\mathrm{DMU}^{0}$. Because investments measure the change in quasi-fixed factors between two periods of time, they are the indication of dynamics incorporated into models. Using the optimal solution $\beta^{*}$ of model (4), input-specific inefficiency for variable input $\left(\mathrm{IEV}_{\mathrm{n}}\right)$ of $\mathrm{DMU}^{0}$ is calculated as:

$\operatorname{IEV}_{n}=\frac{\beta^{*}\left(x_{n}^{0}-x_{n}^{*}\right)}{x_{n}^{0}}, \quad n=1, \ldots, N$

And investment-specific inefficiency $\left(\mathrm{IEF}_{\mathrm{f}}\right)$ of $\mathrm{DMU}^{0}$ is computed as:

$$
\mathrm{IEI}_{f}=\frac{\beta^{*}\left(I_{f}^{*}-I_{f}^{0}\right)}{I_{f}^{0}}, \quad f=1, \ldots, F
$$

Equation (5) suggests that $\mathrm{IEV}_{n}$ takes values between 0 and 1 and Eq. (6) shows that $\mathrm{IEI}_{f}$ will be larger than 0 , where a value of 0 indicates there is no inefficiency in the use of variable inputs or in the investments.

\subsection{Managerial and program dynamic multi-directional inefficiency}

The dynamic MEA approach is next extended to measuring inefficiency attributable to differences in the group-specific frontiers. As proposed by Charnes et al. (1981), firms belonging to different groups (or 'programs') might have different frontiers because of program differences. This paper applies this idea to the context of dynamic MEA

\footnotetext{
${ }^{6}$ The main reason for assuming CRS is that our empirical application focuses on large firms only. Hence, the sample is relatively homogenous in terms of size. CRS inefficiency values are usually slightly larger than VRS inefficiency values; this issue deserves further investigation though.
} 
analysis and develops an approach that distinguishes between dynamic input- and investment-specific multidirectional managerial inefficiency and dynamic input- and investment-specific multidirectional program inefficiency. The first measures dynamic multidirectional inefficiency for variable inputs and investments relative to the frontier made up by the observations from the same group, while the second measures the differences in input- and investmentspecific inefficiency between 'programs', that is the distance between the group-specific frontier and the pooled frontier.

In order to compute dynamic multidirectional managerial inefficiency, first firms in the sample are split into groups denoted by the superscript $g$. In our empirical application, firms are grouped according to their location in one of the regions of the European Union. Dynamic multidirectional managerial inefficiency with respect to variable inputs and investments is computed by first applying Eqs. (2) and (3) to find ideal points within each subsample named $\left(x_{n}^{g *}, I_{f}^{g *}\right)$ and then applying Eq. (4) separately for each group $g$, that is taking the best within-group practices as a benchmark, to obtain the optimal solutions that we call $\beta^{g *}$. Using the optimal solutions, one can compute dynamic input- and investment-specific managerial inefficiency $\left(M I E V_{n}\right.$ and $M I E I_{f}$ hereafter), using Eqs. (5) and (6), where $\beta^{*}$ is substituted with $\beta^{g *}$, and $\left(x_{n}^{*}, I_{f}^{*}\right)$ is substituted by $\left(x_{n}^{g *}, I_{f}^{g *}\right)$.

To obtain dynamic multidirectional program inefficiency, we first need to obtain a new set of observations for variable inputs and investments $\left(x_{n}^{F}, I_{f}^{F}\right)$ that are managerially efficient relative to their group-specific frontier. For variable inputs these frontier values for $\mathrm{DMU}^{0}$ are computed as follows:

$x_{n}^{F}=\left(1-M I E V_{n}\right) \cdot x_{n}^{0}, \quad n=1, \ldots, N$

To obtain frontier values for investments we use the following equation:

$I_{f}^{F}=\left(1+M I E I_{f}\right) \cdot I_{f}^{0}, \quad f=1, \ldots, F$

Then using these new values for inputs and investments, we run Eqs. (2)-(4) once again, but now relative to the frontier composed of all observations in the dataset. This yields the ideal points denoted as $\left(x_{n}^{f *}, I_{f}^{f *}\right)$ and the optimal solutions denoted as $\beta^{f}$. Then using (5) and (6), we can compute dynamic program input- and investment-specific multidirectional inefficiency scores (which we denote as $\mathrm{PIEV}_{n}$ and $\left.\mathrm{PIEI}_{f}\right)$, by substituting $\beta^{*}$ with $\beta^{f *}$, and $\left(x_{n}^{*}, I_{f}^{*}\right)$ by $\left(x_{n}^{f *}, I_{f}^{f *}\right)^{7}$.

\footnotetext{
${ }^{7}$ In order to make the figures of program inefficiency directly comparable with the measures of managerial inefficiency, to compute program inefficiencies in the denominators of Eqs. (5) and (6) instead of frontier values of variable inputs and investments $x_{n}^{F}$ and $I_{f}^{F}$, we use the original values, that is $x_{n}^{0}$ and $I_{f}^{0}$. In this way, both managerial and program inefficiency are stated as a percentage of the same quantity.
}

The concepts of managerial and program dynamic multidirectional inefficiency are illustrated in Fig. 1 for the specific case of two groups of firms ( $g 1$ and $g 2$ ) producing the same quantity of output, using one variable input $x$, and one investment $I$. We assume that point $\left(\mathrm{x}^{0}, \mathrm{I}^{0}\right)$ belongs to the group $g 1$. To obtain the measure of managerial inefficiency for group $g 1$, first an ideal point is found using Eqs. (2) and (3), and then using Eq. (4) point $\left(\mathrm{x}^{0}, \mathrm{I}^{0}\right)$ is projected on the frontier $g 1$ (that is, it is compared with the best observed practices within its own group) by following the path of the largest possible reduction of variable input $x$ and expansion of investment $I$ in the direction of this ideal point. This results in the point on the frontier of group $g 1$ denoted as $\left(\mathrm{x}^{\mathrm{B}}, \mathrm{I}^{\mathrm{B}}\right)$. Next, dynamic managerial inefficiency is measured as the distance between $\left(\mathrm{x}^{0}, \mathrm{I}^{0}\right)$ and $\left(\mathrm{x}^{\mathrm{B}}, \mathrm{I}^{\mathrm{B}}\right)$. Managerial inefficiency for group $g 2$ is computed in a similar way. After the quantities of variable inputs and investments have been transformed according to Eqs. (7) and (8), the point $\left(\mathrm{x}^{\mathrm{B}}, \mathrm{I}^{\mathrm{B}}\right)$ is projected on the frontier spanned by all observations both from group $g 1$ and $g 2$ called $G$ in the direction of ideal point. That is, running Eqs. (2)-(4) yields point $\left(\mathrm{x}^{\mathrm{BP}}, \mathrm{I}^{\mathrm{BP}}\right)$. The distance between $\left(\mathrm{x}^{\mathrm{B}}, \mathrm{I}^{\mathrm{B}}\right)$ and $\left(\mathrm{x}^{\mathrm{BP}}, \mathrm{I}^{\mathrm{BP}}\right)$ is a measure of dynamic program inefficiency. In this graphical example the frontier spanned by the pooled observations coincides with the frontier of group 2 .

The methodology developed in this paper offers several advantages. In particular, it allows for dynamic inefficiency analysis, linking the firms' production decisions over time through capital adjustment and accounting for adjustment costs of investments. Not accounting for dynamics of firms production decisions can lead to biased inefficiency measures especially when firms undertake large investments (Kapelko et al., 2014; Silva et al., 2015). Furthermore, the

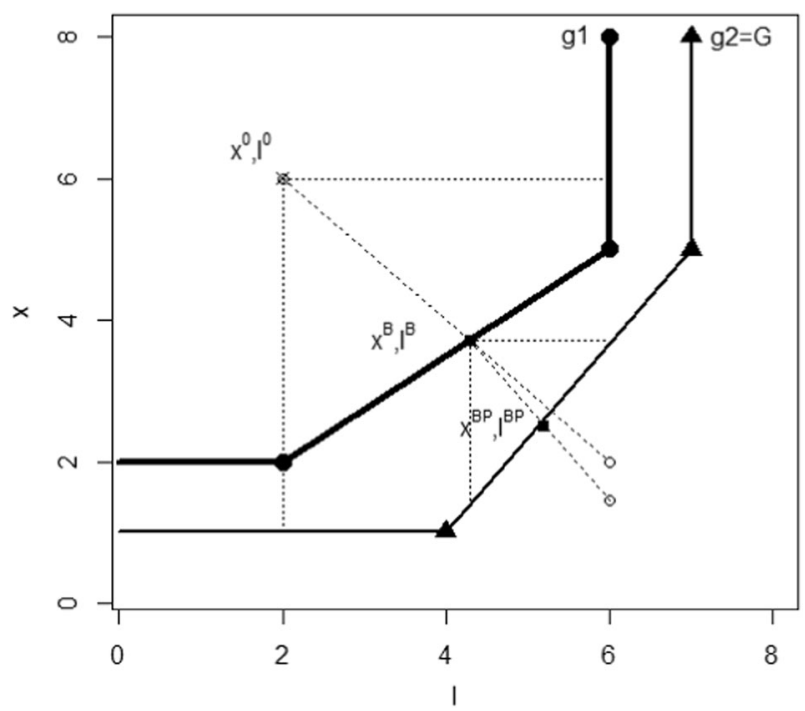

Fig. 1 Illustration of managerial and program dynamic multidirectional inefficiency analysis 
proposed approach enables for a proper analysis and comparison of inefficiency between groups of firms that are characterized by different technologies. The new approach offers also the advantage in separating the benchmark selection from efficiency measurement. It allows selecting benchmarks that are proportional to the potential improvements given by the input specific excesses (Bogetoft and Hougaard 1999), which enables the analysis of potential reduction of each input variable separately.

Nevertheless, while the method offers several advantages fulfilling several properties, we are aware that if other characteristics are important in the investigation, other approaches would be preferred by researchers and practitioners. For example, if more explicit treatment of environmental differences between firms is important, then the method developed by Daraio and Simar (2005) could be more appropriate. Additionally, if the objective is to look into the network structure of firms' production decisions over time, then the best choice would be to apply the dynamic models as suggested by Färe and Grosskopf (1996). When the researcher has Pareto-efficiency in mind when estimating input-specific efficiency, then measures based, for example, on the Russell measure of efficiency (Färe and Lovell 1978) would be a proper choice. Finally, if researcher wishes to analyze the changes in efficiency, scale and technology from one period to the next, then productivity change indicators would be a suitable choice.

\section{Description of the data}

The data used in this article come from the AMADEUS database, which is collected by Bureau van Dijk and contains accounting information on European firms in different industries. This study's dataset concerns large meat manufacturing firms following the EU definition of firms' size, i.e. firms with more than 250 employees and an annual turnover exceeding 50 million euros are categorized as large (European Commission 2003). Meat manufacturing firms represent the NACE group 10.1. The firms in the sample are from three EU regions, i.e. Eastern, Western and Southern Europe, and the sample contains the most important meat processors within each region for which data was available. The region Eastern Europe includes Bulgaria, Croatia, Estonia, Hungary, Poland, Romania, Slovakia and Slovenia; Western Europe includes Austria, Belgium, Finland, France, Germany, Netherlands and Sweden; Southern Europe comprises Italy, Portugal and Spain. Outliers were removed from the sample using the procedure outlined in Simar (2003). The final dataset covering the 2005-2012 period, consists of 1108 observations for Eastern Europe, 1198 observations for Western Europe and 950 observations for Southern Europe.
The computation of dynamic MEA requires information on firms' variable inputs, quasi-fixed inputs, gross investments in quasi-fixed inputs, depreciation and outputs. In this study, two variable inputs are distinguished: materials and labour, which were measured as the costs of these items from firms' profit and loss accounts. One quasi-fixed input was measured as the beginning value of fixed assets from the firms' balance sheets (that is, the end value of the previous year). Gross investments in fixed assets in year $t$ were computed as the beginning value of fixed assets in year $t+$ 1 minus the beginning value of fixed assets in year $t$ plus the value of depreciation in year $t$. One output was distinguished and was proxied as the deflated total revenues from the firms' profit and loss accounts. Finally, the values of depreciation were obtained directly from firms' profit and loss accounts. All aforementioned variables were downloaded from AMADEUS in country-specific currencies and current prices, and were further adjusted using the Purchasing Power Parity (PPP) of the local currency to the US dollar and were deflated using country-specific price indices ${ }^{8}$.

Table 1 presents the descriptive statistics of the variables used in the analysis, both for the whole sample (whole Europe) and for the three regions separately. Detailed data on the development of descriptive statistics over time is presented in the Table 5 in Appendix. Table 1 shows that Western large meat manufacturing firms in the sample obtain, on the average, the highest revenues, followed by Southern and Eastern European firms. Firms in Western Europe also have the highest labor and material costs. In contrast, the firms in Southern Europe have the highest values of fixed assets, on average. Furthermore, Southern European firms, on average, made the largest investments during the study period. Not only the volume of investments in Southern Europe was large, but also the variation within investments as suggested by the large values of standard deviations relatively to their respective averages. This all suggests that overall firms in these three regions have different modes of operating, with Western European firms being more labor- and material-intensive and generating the largest revenues, Southern European firms being more capital- and investment-intensive, and Eastern European firms having the smallest scale of operation as revealed by the smallest values of input-output variables, on average.

\footnotetext{
${ }^{8}$ Revenues were deflated using the producer price index for food manufacturing; material costs using the producer price index for nondurable consumer goods; labour costs using the labour cost index in industry, and fixed assets, gross investments in fixed assets and depreciation by the application of the producer price index for capital goods.
} 
Table 1 Descriptive statistics of the data, 2005-2012 (1000 PPP of local currency to US dollar of 2004)

\begin{tabular}{lllll}
\hline Variable & Eastern & Western & Southern & Europe \\
\hline Fixed assets & $26,487.392(33,569.688)$ & $35,438.248(115,799.415)$ & $47,898.328(130,941.920)$ & $36,027.784(101,909.817)$ \\
Labor cost & $5859.681(6163.791)$ & $22,922.755(59,161.460)$ & $14,604.617(32,168.581)$ & $14,689.304(40,660.047)$ \\
Material cost & $74,036.983(67,575.967)$ & $157,392.007(326,861.074)$ & $114,729.559(154,450.300)$ & $116,579.141(221,420.319)$ \\
Investments & $4941.970(9910.346)$ & $7572.551(29,149.258)$ & $9124.102(37,053.983)$ & $7130.073(27,368.350)$ \\
Depreciation & $2485.013(2756.726)$ & $4069.596(10,816.796)$ & $4306.454(8659.530)$ & $3599.479(8253.738)$ \\
Revenues & $95,881.003(82,855.219)$ & $219,545.195(452,077.994)$ & $157,849.966(229,107.059)$ & $15,9462.151(309,032.115)$ \\
\hline
\end{tabular}

Average values are reported. Standard deviations are in parentheses

\section{Results}

The dynamic multidirectional managerial and program inefficiency of European meat manufacturing firms were estimated separately for each year. The presentation of the results starts with the assessment of managerial inefficiency relative to the region-specific frontier. Next, the difference between the group-specific and pooled frontier was assessed (program inefficiency). Finally, the pooled inefficiency was computed relative to the pooled frontier. The statistical significance of the differences between regions was assessed using the test developed by Simar and Zelenyuk $(2006)^{9}$. The results are reported both for the whole period 2005-2012 and for each year separately.

\subsection{Dynamic multi-directional managerial inefficiency}

The average values of dynamic managerial inefficiency together with the corresponding standard deviations are presented in Table 2, both for each European region separately (Eastern, Western and Southern) and for Europe as a whole.

As reported in Table 2, the dynamic managerial inefficiency of materials on average ranges between 0.150 (Southern) and 0.277 (Eastern). The result of 0.277 for Eastern Europe suggests that meat processing firms in Eastern Europe can reduce the use of materials by 27.7 percent while still producing the same quantity of outputs. The potential for reducing the use of labor is slightly higher in all regions, particularly in Eastern Europe with a potential for reducing labor by $33 \%$. The average values of dynamic managerial inefficiency for investments suggest that meat processing firms could increase their investments by a factor 11.9 (Southern Europe) to 19.4 (Eastern Europe), while still producing the same quantity of outputs. The differences between regions in the inefficiencies for materials, labor and investments are all significant at the critical $1 \%$ level, with the exception of the difference in investment inefficiency between Southern and Eastern Europe. Previous research

\footnotetext{
9 All DEA models were estimated using the GAMS program. Simar and Zelenyuk's (2006) test was applied using software R.
}

Table 2 Dynamic multi-directional managerial input- and investmentspecific inefficiency

\begin{tabular}{|c|c|c|c|c|c|c|}
\hline & \multicolumn{2}{|c|}{ Materials } & \multicolumn{2}{|l|}{ Labor } & \multicolumn{2}{|c|}{ Investments } \\
\hline & Mean & Std. dev. & Mean & Std. dev. & Mean & Std. dev \\
\hline Eastern & 0.277 & 0.142 & 0.330 & 0.124 & 19.409 & 218.180 \\
\hline Western & 0.156 & 0.093 & 0.262 & 0.120 & 17.091 & 62.715 \\
\hline Southern & 0.150 & 0.084 & 0.226 & 0.112 & 11.962 & 53.850 \\
\hline S-Z test & $\mathrm{a}, \mathrm{b}, \mathrm{c}$ & & $\mathrm{a}, \mathrm{b}, \mathrm{c}$ & & $a, b$ & \\
\hline Europe & 0.195 & 0.125 & 0.275 & 0.126 & 16.383 & 135.978 \\
\hline
\end{tabular}

a denotes significant differences between Western and Eastern European countries at the critical $1 \%$ level;

b denotes significant differences between Western and Southern European countries at the critical $1 \%$ level;

c denotes significant differences between Eastern and Southern European countries at the critical $1 \%$ level.

used static approaches to measuring technical efficiency for all inputs in meat processing industry. Shee and Stefanou (2015) and Ali et al. (2009) reported slightly higher values of technical inefficiency for Colombian meat processors and for meat manufacturing firms in India, respectively. Bontemps et al. (2012) found technical inefficiency levels for the poultry industry in France that are similar to our findings. Regarding dynamic inefficiency studies of meat processing industry, our results are similar to those of Kapelko (2017b) findings for the meat processing industry in Poland.

We now analyze dynamic managerial inefficiency for each year of the sample period from 2005 to 2012. The average results are shown in Fig. $2 \mathrm{a}-\mathrm{c}$.

Looking at the figure we first notice that dynamic inefficiency of labor was stable for Eastern and Southern Europe, but slightly decreasing for Western Europe. Also the dynamic inefficiency in the use of materials is decreasing for Western Europe. Eastern Europe exhibits a substantial increase in the inefficiency of the use of materials after 2007. The dynamic investment inefficiency remains at fairly low levels for southern Europe, but is characterized by upward jumps in 2008 and 2011 for Western European firms. This pattern for Western Europe suggests that the gap between the inefficient firms and the firms operating at 
A

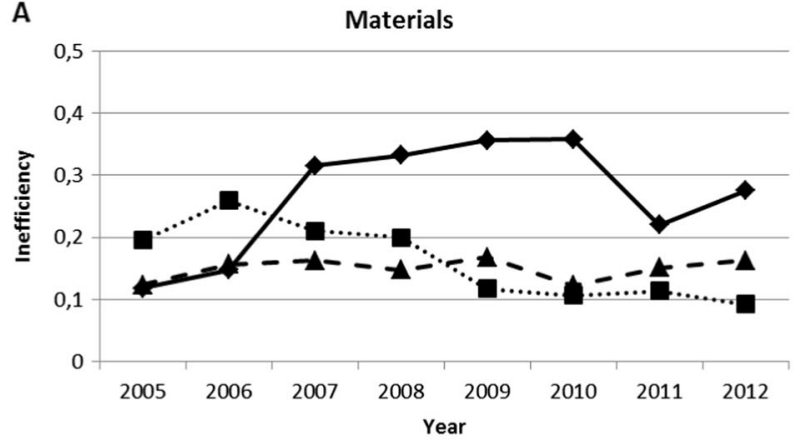

B

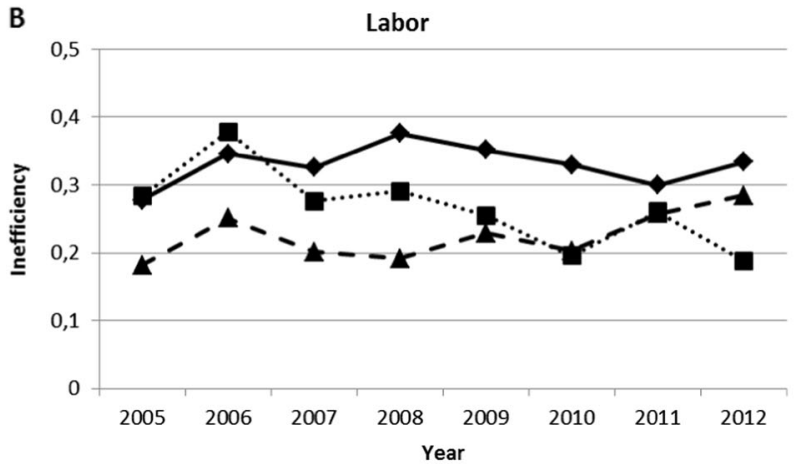

C

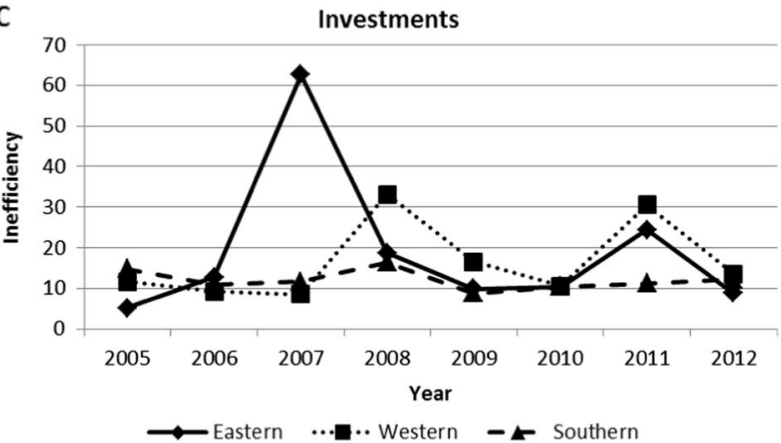

Fig. 2 Evolution of dynamic multi-directional managerial input- and investment-specific inefficiency

the frontier was much higher in these years and could be due to the financial crisis which may have forced firms to cut back investments, and hence leave the technical potential for increasing investments unused. In fact, detailed statistics on the development over time of input-output data contained in Appendix show precisely the case that Western European firms in the sample were cutting back their investments in 2008 and 2011 as compared to 2007 and 2010 respectively, on average. The inefficiency is stable for Eastern European firms, with the exception of the large jump in 2007.

\subsection{Dynamic multi-directional program inefficiency}

Next we assess the difference between the group-specific frontier and the pooled frontier by analyzing program
Table 3 Dynamic multi-directional program input- and investmentspecific inefficiency

\begin{tabular}{|c|c|c|c|c|c|c|}
\hline & \multicolumn{2}{|c|}{ Materials } & \multicolumn{2}{|l|}{ Labor } & \multicolumn{2}{|c|}{ Investments } \\
\hline & Mean & Std. dev. & Mean & Std. dev. & Mean & Std. dev. \\
\hline Eastern & 0.014 & 0.034 & 0.018 & 0.037 & 0.849 & 6.695 \\
\hline Western & 0.184 & 0.113 & 0.185 & 0.090 & 17.244 & 91.622 \\
\hline Southern & 0.164 & 0.099 & 0.182 & 0.084 & 8.409 & 40.170 \\
\hline $\mathrm{S}-\mathrm{Z}$ test & $a, b, c$ & & $\mathrm{a}, \mathrm{b}, \mathrm{c}$ & & $\mathrm{a}, \mathrm{b}, \mathrm{c}$ & \\
\hline Europe & 0.121 & 0.118 & 0.127 & 0.108 & 9.087 & 60.171 \\
\hline
\end{tabular}

a denotes significant differences between Western and Eastern European countries at the critical $1 \%$ level;

b denotes significant differences between Western and Southern European countries at the critical $1 \%$ level;

c denotes significant differences between Eastern and Southern European countries at the critical $1 \%$ level.

inefficiency. The average values of dynamic program inefficiency scores within specific European region as well as for Europe as a whole are summarized in Table 3, together with the values of respective standard deviations.

The results of the dynamic program inefficiency for materials and labor in Table 3 show that the difference between the frontier of meat processing firms in Eastern Europe and the pooled frontier is much smaller than in the case of Western and Southern Europe. For Eastern Europe the difference for materials and labor is only 1.4 and $1.8 \%$, respectively, whereas the difference is 18.4 and $16.4 \%$ (materials) and 18.5 and $18.2 \%$ (labor) for Western and Southern Europe, respectively. These results suggest that the best practice firms in Eastern Europe operate on average closer to the pooled frontiers for labor and materials than the best practice firms in Western and Southern Europe. For investments, a similar pattern is found as for labor and materials, i.e. the gap between the group-specific frontier and the pooled frontier is much smaller for Eastern European firms than for Western and Southern European firms. The results of S-Z test indicate that all differences between regions are statistically significant.

Figure 3a-c provides additional insights into dynamic program inefficiency analysis by summarizing the average values of this indicator for each year of analyzed period.

The evolution of input and investment-specific inefficiency in Fig. 3a-c shows that the dynamic program inefficiency of materials and labor is decreasing over time in Eastern Europe, whereas it is increasing for these inputs, particularly after 2007, for Western and Southern European firms. The increase in the dynamic program inefficiency of labor and materials after 2007 could be due to the financial crisis, which may have caused a drop in demand for meat products and hence, in underutilization of the production capacity. The dynamic inefficiency in the investments is fairly stable for all regions in the period under investigation, 
A

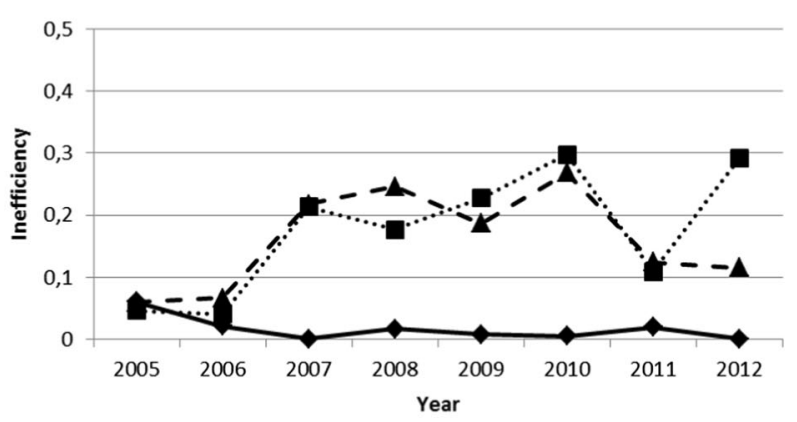

B
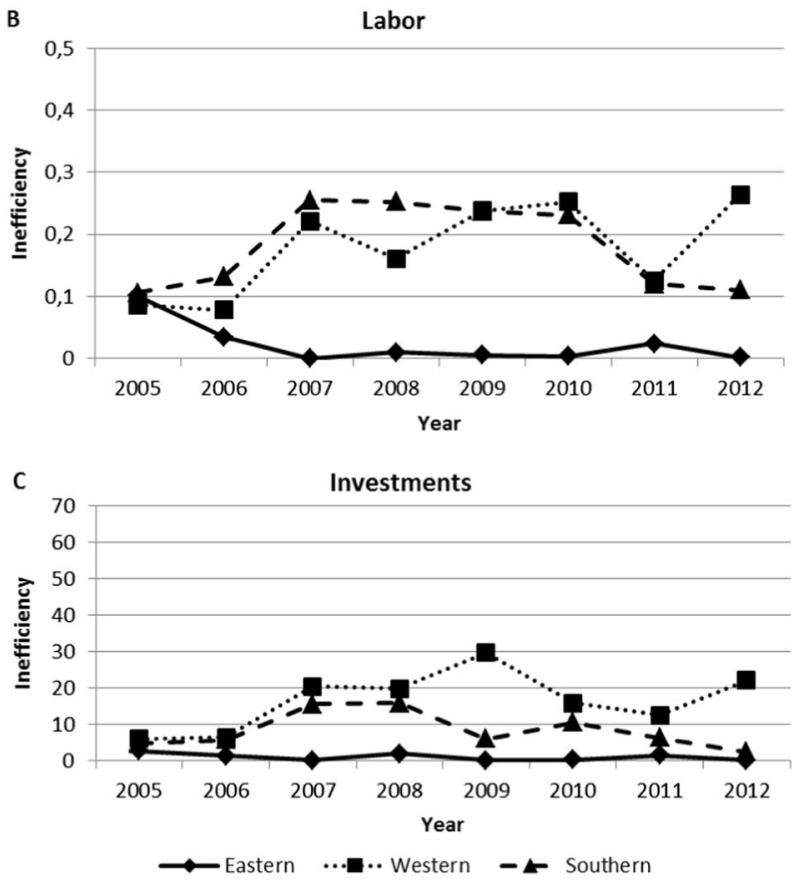

Fig. 3 Evolution of dynamic multi-directional program input- and investment-specific inefficiency

with the exception of the year 2009 for Western European firms.

\subsection{Dynamic multi-directional pooled inefficiency}

In the last step, we computed dynamic multi-directional inefficiency with regard to the pooled frontier. These results are summarized in Table 4, which displays both average values and standard deviations for each region and for Europe as a whole.

Results in Table 4 indicate that firms in Eastern Europe are overall less inefficient in the use of labor and materials. The overall better performance of Eastern European meat processing firms is due to their lower program inefficiency; their managerial inefficiency is higher than for Western and Southern European firms. The overall potential for reducing materials ranges from $29.1 \%$ for Eastern Europe to $34.0 \%$
Table 4 Dynamic multi-directional pooled input- and investmentspecific inefficiency

\begin{tabular}{|c|c|c|c|c|c|c|}
\hline & \multicolumn{2}{|c|}{ Materials } & \multicolumn{2}{|l|}{ Labor } & \multicolumn{2}{|c|}{ Investments } \\
\hline & Mean & Std. dev. & Mean & Std. dev. & Mean & Std. dev. \\
\hline Eastern & 0.291 & 0.138 & 0.349 & 0.124 & 20.259 & 218.791 \\
\hline Western & 0.340 & 0.117 & 0.446 & 0.117 & 34.335 & 145.846 \\
\hline Southern & 0.314 & 0.108 & 0.408 & 0.105 & 20.371 & 89.281 \\
\hline $\mathrm{S}-\mathrm{Z}$ test & $\mathrm{a}, \mathrm{b}, \mathrm{c}$ & & $\mathrm{a}, \mathrm{b}, \mathrm{c}$ & & $a, b, c$ & \\
\hline Europe & 0.316 & 0.124 & 0.402 & 0.123 & 25.471 & 162.702 \\
\hline
\end{tabular}

a denotes significant differences between Western and Eastern European countries at the critical $1 \%$ level;

b denotes significant differences between Western and Southern European countries at the critical $1 \%$ level;

c denotes significant differences between Eastern and Southern European countries at the critical $1 \%$ level.

for Western Europe. For labor the overall inefficiency is higher and ranges from $34.9 \%$ (Eastern Europe) to $44.6 \%$ (Western Europe). The dynamic inefficiency for investment suggests a very large potential for increasing investments, i.e. by a factor of around 20 for Eastern and Southern European firms to a factor of 34 for Western European firms. All these differences are statistically significant as shown by the results of S-Z test. When interpreting the differences in results found between regions, it should be noted that meat manufacturing firms have different characteristics across EU regions. Hence, the lowest values of input- and investment-specific inefficiency found for Eastern European firms in comparison to their Southern and Western counterparts can be associated with their smallest scale of operation in terms of inputs employed and outputs produced. Western European firms, while having the largest values of all inputs and outputs and the largest scale of operation, they also have the highest score for input- and investment-specific inefficiency. This suggests the underutilization of existing capacities by these firms.

The evolution of dynamic pooled inefficiency over the sample period is summarized in Fig. 4.

According to Fig. 4, the dynamic inefficiency of materials shows an increasing trend in all regions until 2010. This is followed by a decrease in 2011 and a slight increase in 2012. This result seems to be in line with a general trend of increasing input costs observed in the EU meat processing sector till 2008 and their further drop from 2009 and then increase from 2012 (European Commission 2016). The inefficiency in labor increases till 2008 in all regions, followed by a decrease till 2011. The decrease in the dynamic inefficiency in labor after 2008 could be attributable to the financial crisis which may have induced companies to operate more efficiently and to reduce the number of employees. In fact, from 2008 the EU meat processing 

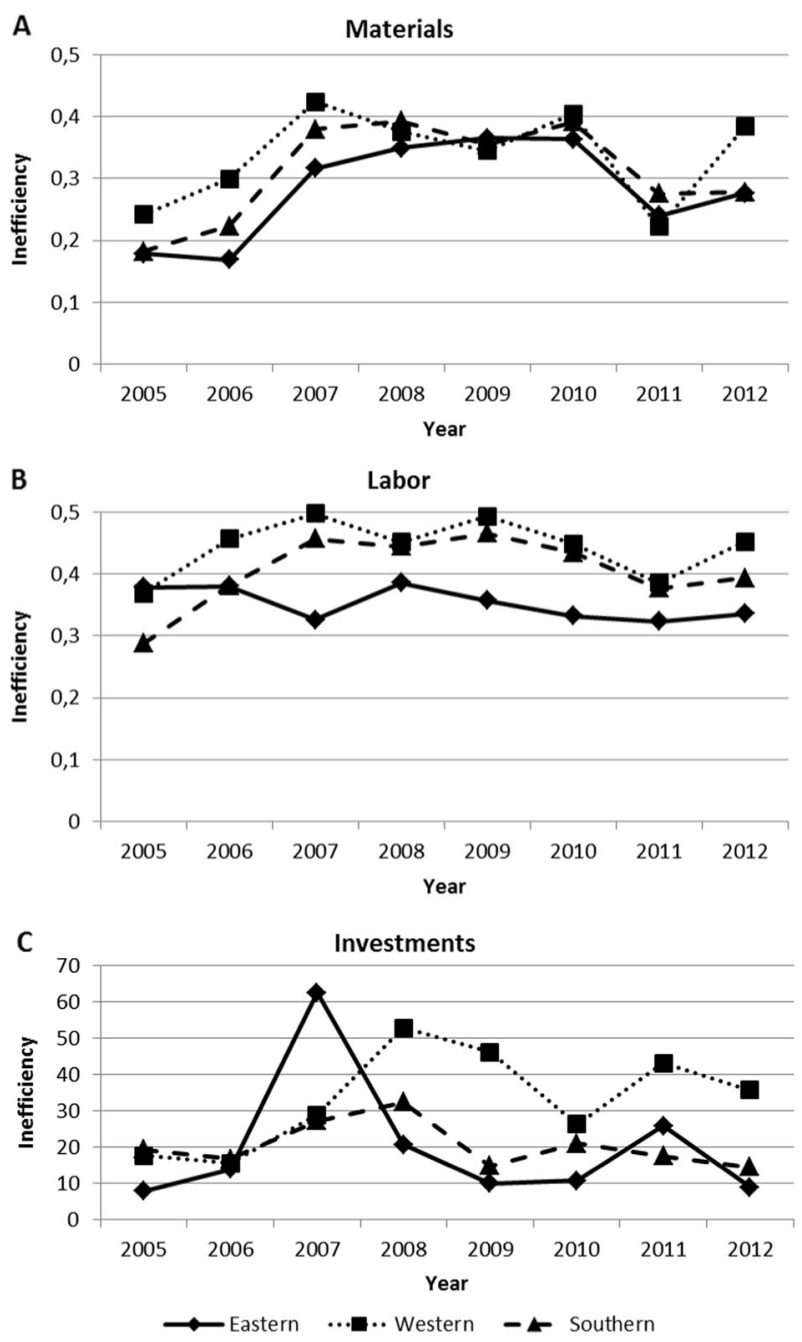

Fig. 4 Evolution of dynamic multi-directional pooled input- and investment-specific inefficiency

sector increased its labor productivity through steady growth in value added and a slight decrease in the number of employees (European Commission 2016). The overall investment inefficiency is also peaking especially for Western European firms in 2008, i.e. the 1st year of the financial crisis, suggesting that firms in this region were not using the economic potential for investing. The crisis have made the meat manufacturing firms in this region more reluctant to invest, which is highlighted by the data in Appendix which shows Western European firms in the sample decreasing their investment value in 2008 as compared to 2007, on average.

\section{Conclusions}

This paper contributes to the literature by developing an approach to modelling input- and investment-specific dynamic inefficiency for groups of firms based on the dynamic multidirectional inefficiency analysis within the context of Data Envelopment Analysis. The framework allows for distinguishing between dynamic managerial inefficiency (that measures the distance to the firms' groupspecific frontier) and dynamic program inefficiency (that assesses the difference between the group-specific frontier and the pooled frontier) for each variable input and investment employed in the firms' production process. The approach is applied to a sample of large meat processing firms from three regions in the European Union (Eastern, Western and Southern) over the period 2005-2012.

The results highlight significant differences in different dimensions of dynamic inefficiency, not only between regions analyzed, but also between different inputs employed and for investments. The results show that the frontier for Eastern European firms for all inputs is almost identical to the pooled frontier spanned by all firms in three regions. This suggests that dynamic managerial inefficiency is a much larger source of inefficiency for Eastern European firms than dynamic program inefficiency. The results also show that Western European firms have the highest values of dynamic program and pooled inefficiency for all inputs, and that Southern European firms perform relatively best for dynamic managerial inefficiency with regard to all inputs analyzed. The comparison of dynamic inefficiencies for different inputs indicate that investments are the most inefficient input, followed by labor and materials.

The results of this study suggest differences in the technology employed by Eastern, Western and Southern European firms for all inputs and investments as reflected by the differences in program inefficiency measures. Moreover, the finding of the lowest average dynamic managerial inefficiency for all inputs for Southern European firms suggests that these firms are more homogeneous in terms of their performance than firms in other regions. The highest values of average dynamic managerial inefficiency for all inputs for Eastern European firms suggests that these firms are less homogeneous in terms of their performance for every input and investment employed in the production process. Hence, the best practice firms operate close to or at the pooled frontier, but the majority of these firms operate further away from their group-specific frontier. This implies that the best performing companies for all inputs in the pooled sample are mainly from Eastern Europe and these firms are more often located on the pooled frontier. On the contrary, Western European firms have the highest values of dynamic program inefficiency, which implies that for these firms the differences between group-specific and pooled frontier are the largest.

The results of this study can be used by different groups of decision makers to improve the performance of meat manufacturing firms and designing successful strategies to 
prosper in liberalized and regulated markets. Since Eastern European meat manufacturing firms suffer more from dynamic managerial inefficiency, incentives should focus more on improving the performance within these companies. Firms could enhance the efficiency of the use of labor by for example, introducing incentive contracts or in-house training for their employees. Lower efficiency of the use of materials could be due to waste of materials throughout the production process. Hence, fine tuning the process and identifying and improving the stages of the process where losses occur could reduce the inefficiency in the use of materials. Finally, inefficiency in the investments could be due to high internal adjustment costs associated with investments, e.g. high internal costs associated with the process of learning to use new technologies or search costs. Hence, firms could reduce these investment inefficiencies by a better training of their personnel in case of the introduction of new technologies. The inefficiency in investments may also be due to financial manager's unawareness of the investment potential and the firm's effort could also focus on upgrading its financial management, e.g. through education or better access to information. Southern and Western European firms have lower values of dynamic managerial inefficiency, but very high values of dynamic program inefficiency. Hence, in these regions incentives should focus on improving the technology employed by these firms. Policy makers can contribute to technology improvement of firms by introducing incentives (e.g. tax incentives or investment subsidies) for adopting new technologies and by investing in education of the country's labor force. Furthermore, increasing the firm's own R\&D investments may enable a more rapid technological improvement. The high values of inefficiency for investments in all regions suggests that capital markets might serve as a barrier to investment. Also, the relatively high values of inefficiency for labor imply that labor market imperfections could be addressed by policy makers, e.g. by enabling firms to more easily contract their labor force in times of economic downturn.

Future research efforts can apply the approach developed in this paper to other industrial sectors, including other sectors within the food manufacturing industry like dairy processing or oils and fats industry. While this paper shows that Eastern, Western and Southern European meat manufacturing firms differ in terms of their managerial and program inefficiency, more research is needed to analyze whether these groups of firms differ in terms of productivity change and its decomposition. Such an analysis could provide insight into the relative speed with which firms in different regions are improving their competitiveness over time. Also, future research could look into more detailed groups of meat manufacturing firms composed of firms from countries within regions. From a conceptual point of view, future research could extend the models developed in the paper by accounting for the sample bias using bootstrap methods or allowing for a more explicit treatment of environmental differences following the line of research suggested by Daraio and Simar (2005) and extended in the MEA context by Baležentis and De Witte (2015).

Acknowledgements This research has been funded by the National Science Centre in Poland, decision number DEC-2013/11/D/HS4/ 00252. The part of calculations for this article was made at the Wroclaw Centre for Networking and Supercomputing (http://www. wcss.wroc.pl).

\section{Compliance with ethical standards}

Conflict of interest The authors declare that they have no competing interests.

Open Access This article is distributed under the terms of the Creative Commons Attribution 4.0 International License (http://crea tivecommons.org/licenses/by/4.0/), which permits unrestricted use, distribution, and reproduction in any medium, provided you give appropriate credit to the original author(s) and the source, provide a link to the Creative Commons license, and indicate if changes were made.

\section{Appendix}

Table 5

Table 5 Development of descriptive statistics of the data over time (2005-2012)

\begin{tabular}{lllllllll}
\hline Variable & 2005 & 2006 & 2007 & 2008 & 2009 & 2010 & 2011 & 2012 \\
\hline Fixed assets & & & & & & & & \\
Eastern & $21,397.576$ & $22,930.785$ & $23,977.125$ & $28,298.076$ & $28,782.921$ & $28,116.285$ & $29,194.136$ & $25,456.040$ \\
Western & $47,049.094$ & $41,185.713$ & $43,953.582$ & $36,342.527$ & $28,593.537$ & $29,102.968$ & $29,897.378$ & $33,485.543$ \\
Southern & $28,350.629$ & $36,520.958$ & $39,195.787$ & $39,612.466$ & $57,864.003$ & $57,527.199$ & $55,941.561$ & $60,459.232$
\end{tabular}


Table 5 continued

\begin{tabular}{|c|c|c|c|c|c|c|c|c|}
\hline Variable & 2005 & 2006 & 2007 & 2008 & 2009 & 2010 & 2011 & 2012 \\
\hline \multicolumn{9}{|l|}{ Labor cost } \\
\hline Eastern & 5947.674 & 5833.255 & 5585.038 & 6618.063 & 6249.512 & 5867.643 & 5735.147 & 5122.039 \\
\hline Western & $32,485.264$ & $28,060.870$ & $28,560.410$ & $22,512.214$ & $18,074.693$ & $18,257.811$ & $18,746.158$ & $21,580.613$ \\
\hline Southern & $12,177.556$ & $13,384.304$ & $13,580.038$ & $13,506.316$ & $15,567.619$ & $14,946.606$ & $16,674.607$ & $16,048.333$ \\
\hline \multicolumn{9}{|c|}{ Material cost } \\
\hline Eastern & $65,829.200$ & $67,269.953$ & $66,102.467$ & $74,361.900$ & $75,512.609$ & $75,095.575$ & $77,877.247$ & $83,857.564$ \\
\hline Western & $186,389.305$ & $165,422.381$ & $175,339.625$ & $163,924.332$ & $134,456.840$ & $135,961.436$ & $152,141.540$ & $159,825.534$ \\
\hline Southern & $86,180.068$ & $101,259.254$ & $99,172.805$ & $104,172.659$ & $116,316.739$ & $123,609.008$ & $134,113.823$ & $141,079.594$ \\
\hline \multicolumn{9}{|c|}{ Investments } \\
\hline Eastern & 3638.316 & 6257.439 & 5406.619 & 6501.310 & 4583.181 & 4902.839 & 4628.684 & 3927.795 \\
\hline Western & $12,058.931$ & 7296.022 & $14,182.255$ & 6535.374 & 4642.168 & 6270.570 & 6182.222 & 5145.279 \\
\hline Southern & 6483.058 & 8565.990 & 6612.873 & $19,050.793$ & 6694.084 & 5406.964 & $11,280.201$ & 8142.575 \\
\hline \multicolumn{9}{|c|}{ Depreciation } \\
\hline Eastern & 1999.657 & 2045.996 & 2315.884 & 2789.383 & 2611.894 & 2766.573 & 2663.718 & 2321.946 \\
\hline Western & 4892.042 & 4550.794 & 4900.192 & 3881.550 & 3219.845 & 3668.731 & 3775.852 & 4125.796 \\
\hline Southern & 2880.753 & 3565.386 & 3918.846 & 3894.054 & 4744.524 & 5236.317 & 4792.257 & 4894.573 \\
\hline \multicolumn{9}{|l|}{ Revenues } \\
\hline Eastern & $87,949.625$ & $87,332.185$ & $88,686.514$ & $98,509.929$ & $99,689.374$ & $98,195.225$ & $97,663.400$ & $102,538.137$ \\
\hline Western & $275,640.051$ & $245,320.672$ & $251,920.008$ & $219,463.176$ & $188,558.389$ & $190,432.759$ & $201,285.239$ & $211,469.791$ \\
\hline Southern & $124,320.469$ & $145,654.421$ & $142,453.452$ & $138,961.669$ & $165,276.562$ & $170,854.441$ & $178,961.815$ & $183,355.791$ \\
\hline
\end{tabular}

Average values reported

\section{References}

Ali J, Singh SP, Ekanem E (2009) Efficiency and productivity changes in the Indian food processing industry: determinants and policy implications. Int Food Agribus Manage Rev 12:43-66

Asmild M, Hougaard JL, Kronborg D, Kvist HK (2003) Measuring inefficiency via potential improvements. J Prod Anal 19:59-76

Asmild M, Pastor JT (2010) Slack free MEA and RDM with comprehensive efficiency measures. Omega 38:475-83

Asmild M, Baležentis T, Hougaard JL (2016) Multi-directional program efficiency: the case of Lithuanian family farms. J Prod Anal 45:23-33

Baležentis T, De Witte K (2015) One- and multi-directional conditional efficiency measurement-efficiency of Lithuanian family farms. Eur J Oper Res 245:612-622

Battese GE, Prasada Rao DS, O'Donnell ChJ (2004) A metafrontier production function for estimation of technical efficiencies and technology gaps for firms operating under different technologies. J Prod Anal 21:91-103

Beltrán-Esteve M, Reig-Martínez E (2014) Comparing conventional and organic citrus grower efficiency in Spain. Agric Syst 129:115-123

Bogetoft P, Hougaard JL (1999) Efficiency evaluations based on potential (non-proportional) improvements. J Prod Anal 12 (3):233-247

Bogetoft P, Hougaard JL (2004) Super efficiency evaluations based on potential slack. Eur J Oper Res 152:14-21

Bontemps C, Nauges C, Réquillart V, Simioni N (2012) Food safety regulation and firm productivity: evidence from the French food industry. IDEI Working papers. http://www.idei.fr/doc/by/ requillart/foodsafety.pdf. Accessed 20 Aug 2017
Charnes A, Cooper WW, Rhodes E (1981) Evaluating program and managerial efficiency: an application of data envelopment analysis to program follow through. Manag Sci 27(6):668-697

Chen C-M (2009) A network-DEA model with new efficiency measures to incorporate the dynamic effect in production networks. Eur J Oper Res 194:687-699

Daraio C, Simar L (2005) Introducing environmental variables in nonparametric frontier models: a probabilistic approach. J Prod Anal 24:93-121

European Commission (2003) Recommendation concerning the definition of micro, small and medium-sized enterprises. Off $\mathrm{J}$ Eur Union 46:36-41. http://eur-lex.europa.eu/LexUriServ/LexUriServ.do?uri=OJ:L:2003:124:0036:0041:EN:PDF Accessed 20 Jan 2016

European Commission (2011) Study on the competitiveness of the European meat processing industry. Publication Office of the European Union, Luxembourg, http://ec.europa.eu/enterprise/ sectors/food/files/report_compmeat_en.pdf Accessed 20 Jan 2016

European Commission (2016) The competitive position of the European food and drink industry. Publication Office of the European Union, Luxembourg, http://ec.europa.eu/DocsRoom/ documents/15496/attachments/1/translations Accessed 20 Aug 2017

Eurostat (2015) Short-term business statistics. http://ec.europa.eu/ eurostat/web/short-term-business-statistics. Accessed 20 Jan 2016

Fallah-Fini S, Triantis K, Johnson AL (2014) Reviewing the literature on non-parametric dynamic efficiency measurement: state-of-theart. J Prod Anal 41:51-67

Färe R, Lovell CAK (1978) Measuring the technical efficiency of production. J Econ Theory 19:150-162 
Färe R, Grosskopf S (1996) Intertemporal production frontiers: with dynamic DEA.. Kluwer Academic Publishers, Boston

Färe R, Grosskopf S (2010) Directional distance functions and slacks-based measures of efficiency. Eur J Oper Res 200 (1):320-322

Fukuyama H, Weber WL (2009) A directional slacks-based measure of technical inefficiency. Socio Econ Plan Sci 43 (4):274-287

Fukuyama H, Weber WL (2015) Measuring Japanese bank performance: a dynamic network DEA approach. J Prod Anal 44:249-264

Gómez-Limón JA, Picazo-Tadeo AJ, Reig-Martínez E (2012) Ecoefficiency assessment of olive farms in Andalusia. Land Use Policy 29(2):395-406

Kapelko M, Oude Lansink A, Stefanou SE (2014) Assessing dynamic inefficiency of the Spanish construction sector pre- and postfinancial crisis. Eur J Oper Res 237(1):349-357

Kapelko M (2017a) Measuring inefficiency for specific inputs using Data Envelopment Analysis: evidence from construction industry in Spain and Portugal. Cent Eur J Oper Res. https://doi.org/ 10.1007/s10100-017-0473-z

Kapelko M (2017b) Dynamic versus static inefficiency assessment of the Polish meat processing industry in the aftermath of the European Union integration and financial crisis. Agribus 33:505-521.

Kapelko M, Oude Lansink A (2017) Dynamic multi-directional inefficiency analysis of European dairy manufacturing firms. Eur $\mathbf{J}$ Oper Res 257:338-344

Kapelko M, Horta IM, Camanho AS, Oude Lansink A (2015) Measurement of input-specific productivity growth with an application to the construction industry in Spain and Portugal. Int J Prod Econ 166:64-71

Mahlberg B, Sahoo BK (2011) Radial and non-radial decomposition of Luenberger productivity indicator with an illustrative application. Int J Prod Econ 131:721-726

Mancebón MJ, Calero J, Choi Á, Pérez Ximénez-de-Embún D (2012) The efficiency of public and publicly subsidized high schools in Spain: evidence from PISA-2006. J Oper Res Soc 63:1516-1533

Nemoto J, Goto M (2003) Measurement of dynamic efficiency in production: an application of data envelopment analysis to Japanese electric utilities. J Prod Anal 19:191-210

Nemoto J, Goto M (1999) Dynamic Data Envelopment Analysis: modeling intertemporal behavior of a firm in the presence of productive inefficiencies. Econ Lett 64:51-56
O'Donnell CHJ, Prasada Rao DS, Battese GE (2008) Metafrontier frameworks for the study of firm-level efficiencies and technology ratios. Empir Econ 34:231-255

Oude Lansink A, Ondersteijn Ch (2006) Energy productivity growth in the Dutch greenhouse industry. Am J Agric Econ 88 (1): $124-132$

Portela SMC, Thanassoulis E (2001) Decomposing school and schooltype efficiency. Eur J Oper Res 132:357-373

Serra T, Oude Lansink A, Stefanou SE (2011) Measurement of dynamic efficiency: a directional distance function parametric approach. Am J Agric Econ 93(3):756-767

Shee A, Stefanou SE (2015) Endogeneity corrected stochastic production frontier and technical efficiency. Am J Agric Econ 97:939-952

Silva E, Stefanou SE (2003) Nonparametric dynamic production analysis and the theory of cost. J Prod Anal 19(1):5-32

Silva E, Stefanou SE (2007) Dynamic efficiency measurement: theory and application. Am J Agric Econ 89(2):398-419

Silva E, Oude Lansink A, Stefanou SE (2015) The adjustment-cost model of the firm: duality and productive efficiency. Int J Prod Econ 168:245-256

Simar L (2003) Detecting outliers in frontier models: a simple approach. J Prod Anal 20(3):391-424

Simar L, Zelenyuk V (2006) On testing equality of distributions of technical efficiency scores. Econom Rev 25(4):497-522

Wijnands JHM, Van der Meulen BMJ, Poppe KJ (2007) Competitiveness of the European food industry: an economic and legal assessment. Publication Office of the European Union, Luxembourg. http://bookshop.europa.eu/en/competitivenessof-the-european-food-industry-pbNB7807110/ Accessed 20 Aug 2017

Van Horne PLM, Bondt N (2013) Competitiveness of the EU poultry meat sector. LEI Report 2013-068. LEI Wageningen UR, The Hague

Yao X, Zhou H, Zhang A, Li A (2015) Regional energy efficiency, carbon emission performance and technology gaps in China: a meta-frontier non-radial directional distance function analysis. Energy Policy 84:142-154

Zhang N, Kong F, Yu Y (2015) Measuring ecological total-factor energy efficiency incorporating regional heterogeneities in China. Ecol Indic 51:165-172

Zhu N, Wang B, Wub Y (2015) Productivity, efficiency, and nonperforming loans in the Chinese banking industry. Soc Sci J $52: 468-480$ 